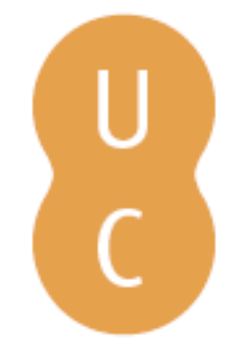

\title{
pommalina
}

\section{Reflexos albertianos no Renascimento Português: a descriptio urbis romae, o matemático Francisco de Melo e um mapa virtual de Portugal em 1531}

\author{
Autor(es): $\quad$ Moreira, Rafael \\ Publicado por: Imprensa da Universidade de Coimbra \\ URL \\ persistente: URI:http://hdl.handle.net/10316.2/36684 \\ DOI: $\quad$ DOI:http://dx.doi.org/10.14195/978-989-26-1015-3_22 \\ Accessed : $\quad$ 26-Apr-2023 15:28:00
}

A navegação consulta e descarregamento dos títulos inseridos nas Bibliotecas Digitais UC Digitalis, UC Pombalina e UC Impactum, pressupõem a aceitação plena e sem reservas dos Termos e Condições de Uso destas Bibliotecas Digitais, disponíveis em https://digitalis.uc.pt/pt-pt/termos.

Conforme exposto nos referidos Termos e Condições de Uso, o descarregamento de títulos de acesso restrito requer uma licença válida de autorização devendo o utilizador aceder ao(s) documento(s) a partir de um endereço de IP da instituição detentora da supramencionada licença.

Ao utilizador é apenas permitido o descarregamento para uso pessoal, pelo que o emprego do(s) título(s) descarregado(s) para outro fim, designadamente comercial, carece de autorização do respetivo autor ou editor da obra.

Na medida em que todas as obras da UC Digitalis se encontram protegidas pelo Código do Direito de Autor e Direitos Conexos e demais legislação aplicável, toda a cópia, parcial ou total, deste documento, nos casos em que é legalmente admitida, deverá conter ou fazer-se acompanhar por este aviso.

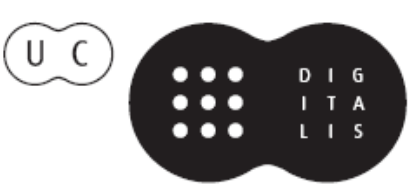


IMPRENSA DA

UNIVERSIDADE

DE COIMBRA

COIMBRA

UNIVERSITY

PRESS

\section{NA GÉNESE DAS RACIONALIDADES MODERNAS II}

Em torno de Alberti e do Humanismo

MÁRIO KRÜGER et alii

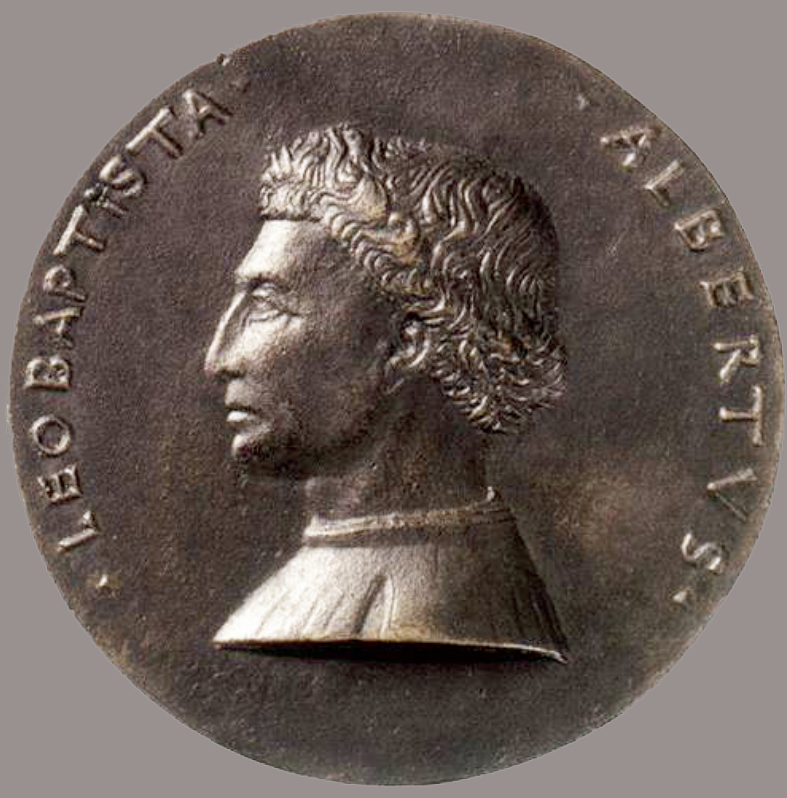




\section{REFLEXOS ALBERTIANOS NO RENASCIMENTO \\ PORTUGUES. A DESCRIPTIO URBIS ROMAE, O MATEMÁTICO FRANCISCO DE MELO E UM MAPA VIRTUAL DE PORTUGAL EM 1531}

Rafael Moreira

\section{Resumo}

Partindo da análise dos contributos albertianos na "Oração" que proferiu na abertura das Cortes de 1535, examina-se brevemente a vida e a obra do grande matemático Francisco de Melo - em particular o "Códice de Hamburgo", a que atribuímos a data de 1531 e a função dum verdadeiro mapa virtual codificado de Portugal, inspirado na Descriptio Urbis Romae de Alberti (c.1450) -, para chegar à conclusão de que foi ele o introdutor de Alberti no nosso país, e fazer um retrospeto das suas influências sobre a arte, a arquitetura, e a tratadística portuguesas dos séculos XVI e XVII.

Francisco de Melo; Alberti; Cartografia; Arquitetura.

\section{Résumé}

En partant de l'analyse des apports albertiens à l'Oraison proférée par lui lors de l'ouverture des Cortes de 1535, on examine la vie et l'oeuvre du grand mathématicien Francisco de Melo - en particulier le "Codex de Hambourg", auquel on attribue la date de 1531 et la fonction d'une vraie carte virtuelle codifiée du Portugal, inspirée de la Descriptio urbis Romae d'Alberti (1450 c.) -, pour arriver à la conclusion qu'il a introduit Alberti dans notre pays, ainsi que 
donner une vue sommaire de ses influences sur l'art, l'architecture et les traités portugais des XVIe et XVIIe siècles Francisco de Melo; Alberti; Cartographie; Architecture

\begin{abstract}
Based in a manuscript containing the coordinates of 1531 placenames in Portugal, this article shows that it must be attributed to this year, to the humanist-mathematician Francisco de Melo, and composes a virtual map of the entire country according to the ideas expressed by Alberti in his "Descriptio Urbis Romae" (1450). It is a landmark in the introduction of Albertian thought in Portugal - through Paris, where Melo studied from 1514 to 1520 - and the start of a century-long Albertian influence in architectural theory and buildings both in Portugal as in Brazil.

Francisco de Melo; Alberti; Cartography; Architecture.
\end{abstract}


No domingo 13 de junho de 1535, nos "balcões que atravessam do Palácio contra o laranjal" - a atual Galeria das Damas - em Évora, o rei D. João III procedia à abertura das Cortes, após ter feito jurar como herdeiro o pequeno príncipe $\mathrm{D}$. Manuel, de pouco mais de 3 anos de idade.

O discurso de abertura foi pronunciado em nome do Rei, em português e não em latim como era habitual, por um de seus oradores preferidos: o Doutor Francisco de Melo, nobre eborense que, apesar de sacerdote, era membro do seu conselho, capelão-mor do paço, e ilustríssimo matemático e cientista, professor de Matemáticas do jovem infante-cardeal D. Henrique, irmão do rei; além de um grande humanista, amigo do flamengo Nicolau Clenardo e de todo o círculo humanístico da Évora do Renascimento. Nascido c. 1490 , desde muito novo a sua inteligência tinha chamado a atenção do rei D. Manuel, que o mandara estudar em Paris.

O discurso - que deve ter levado umas 3 horas a ser lido - foi um enorme sucesso: embora não tenha sido impresso, existe uma dezena de cópias da época ou pouco posteriores. Melo introduz um corte radical no pensamento político português, substituindo a doutrina medieval (e manuelina) da origem divina do poder real - que ele próprio ainda sustentava na oração de abertura das Cortes de Torres Novas em 1525 - pela ideia da solidariedade entre a natureza e a sociedade, composta de "membros inferiores" (os camponeses, sobretudo) e "superiores" (os agentes do poder real) - os pés e as mãos - com os seus "braços" (os oficiais de justiça e militares), e uma "cabeça", o Rei em que todos os sentidos se concentram e zelam pelo bem comum: o panegírico da monarquia paternalista tal como D. João III a estabelecera, de que a reunião periódica de Cortes e o juramento do príncipe herdeiro eram os pilares fundamentais.

A imagem da sociedade como um corpo humano em que todos colaboram vem em linha reta da conceção de S. Paulo do corpo místico sob a visão neoplatónica do governo de "letrados ou amigos das letras", tal como da leitura do Enchiridion de Erasmo (e lembremos que Marcel Bataillon escreveu que Portugal era em 1533 "o país mais erasmiano da Europa”...): o que torna este discurso de 1535 num verdadeiro manifesto, quase subversivo.

Tanto mais que a metáfora paulino-erasmista do corpo não é aí tomada apenas como noção metafísica mas no seu sentido mais concreto, mate- 
rial, de cânon da beleza e medida de todas coisas do universo: o sentido vitruviano-albertiano por excelência. Ao nomear, com detalhe de anatomista - ou de escultor - o assento dos pés, o toro do corpo tam robusto e largo, a longura dos braços, as luzernas dos principaes sentidos, compasso de tão desvairados membros, Francisco de Melo tinha diante dos olhos uma gravura como as do bomo ad quadratum e ad circulum de Vitrúvio, senão as esculturas de Chanterene no alto da fachada da igreja da Graça. Desde seu Proémio, ele estabelece a relação física entre a harmonia da sociedade e perfeição do corpo humano com a beleza do mundo, colocando assim as considerações estéticas no centro da sua reflexão política.

Longe dos preceitos técnicos de Vitrúvio ou Sagredo - que lera, com toda a certeza -, é à visão mais filosófica e sistemática, com uma postura ético-política de rigor, do De re aedificatoria de Leon Battista Alberti (Florença, 1485) ${ }^{604}$ que o orador doutrinário foi buscar a estrutura da obra e do pensamento albertianos, e soube tirar todo o partido possível do seu conceito fundamental do corpo como "um edifício", tanto de arquitetura como social, adaptando-o à realidade do país.

A prova é-nos dada logo a seguir: no Exórdio - o começo da Narratio, em que apresenta os temas essenciais do discurso -, após a devida evocação do Deus-demiurgo, autor das maravilhosas obras da natureza, Melo enumera as três formas de harmonia em que reside a perfeição universal:

a variedade sem desordem, antes de mais. Sabe-se o valor essencial da varietas na teoria albertiana por oposição à unitas, do equilíbrio das duas nascendo o bom uso e a comodidade do seu utilizador: a commoditas, um termo que Alberti prefere ao vitruviano de utilitas. Por analogia com a Música, varietas designa a diversidade das linhas e ângulos perfeitamente dispostos (Liv. I, cap. 10) de modo a não criar espaços disformes ou mal proporcionados. Regressando no final de seu tratado às questões gerais de Estética, Alberti identifica a "correta variedade" com a teoria

604 A seguir à editio princeps florentina, há uma edição de Estrasburgo em 1511 e outra de Paris, por Geoffroy Tory, em 1512, que Melo deve ter utilizado. As traduções em italiano só começam em Veneza, por Pietro Lauro, em 1546, e a célebre de Cósimo Bártoli de Florença, em 1550 (John Bury e Paul Breman, Writings on Architecture Civil and Military c1460 to 1640, De Graaf Publishers, 2000). 
das ordens como expressão do estatuto social do dono da casa: o que explica por que Melo põe em oposição variedade e desordem, que não têm correspondente em Vitrúvio.

a suficiência sem defeito, a seguir. Trata-se aqui de tudo que baste a satisfazer as necessidades dos indivíduos, ou seja a necessitas (um termo que engloba os vitruvianos firmitas e soliditas). A falta, ou "defeito", de uma destas condições colocaria em perigo a segurança contra os rigores do clima ou os perigos da vida humana, ou seja da própria sociedade. Para Melo, são problemas ligados ao abastecimento público - no que alude sem dúvida à crise que se seguiu ao sismo de 1531 - e um elogio à construção do Aqueduto da Água de Prata em Évora por D. João III, que seria inaugurado em 1537, quando recebeu do Senado da cidade o título imperial romano de Pater Patriae.

e a conformidade sem repugnância, por fim. Nível estético por excelência, trata-se bem do conceito central albertiano de concinnitas, sobre o qual tanto tem sido escrito. Melo ignora a venustas vitruviana, como a qualidade de agradar oposta à de rejeição, e a traduz com perfeita compreensão de seu sentido por "conformidade": a conveniência, acordo ou harmonia entre as partes. 605

Vemos que a célebre "tripartição aristotélica", para usarmos a expressão de Françoise Choay, ou tríade vitruviana, provém, no discurso de 1535, diretamente do sentido moral que lhe foi dado por Alberti e bem traduzido por Francisco de Melo pelos termos de ordem, diligencia e concordia. A beleza artística e justiça social assim se conjugam sob uma mesma fórmula, baseada na imitação dos princípios numéricos que regem a natureza (e que não podiam deixar indiferente o matemático apaixonado que era Melo). O seu antropomorfismo moralizado resolve-se, pois, na série de "leis" racionais que regulam tanto a Respública - o conjunto de alvarás emanados do Príncipe - quanto a perfeição das obras saídas da mão do homem.

605 Para uma análise mais aprofundada da oração de Francisco de Melo de 1535 veja-se a nossa tese de Doutoramento em História da Arte na Universidade Nova de Lisboa, "A Arquitetura do Renascimento no Sul de Portugal: a encomenda régia entre o moderno e o romano" (texto mimeograf.), vol. 1, Lisboa, 1991, pp. 198-210. 
Não é decerto por acaso que nestes mesmos exatos anos de 1530 a 40 em que se assiste ao aparecimento e difusão entre nós do nome de "Alberto", ou Leon Battista Alberti - se divulga entre os intelectuais portugueses, e em particular eborenses, um neologismo que desaparece em seguida: o de músico. Não se trata, é evidente, do simples músico, ou tocador de um instrumento musical, nem da pessoa ligada às Musas, ou cultivo das artes, mas de algo de bem mais complexo e refinado: é aquele que torna visível através de seus atos, gostos e maneira de ser, de sua própria aparência e boas maneiras, a harmonia musical da perfeição rítmica do mundo. Que é o reflexo vivo e simples da "música das esferas" platónica, do pleno equilíbrio entre o ideal de vida e a consonância da alma do mundo com a sociedade e com cada indivíduo. Nas páginas do De re aedificatoria dedicadas a fixar as relações numéricas do acorde musical como princípio universal da beleza e da proporção (Liv. IX, cap. 5) os sons, suas medidas, escalas e intervalos são aquilo "que fazem com que os olhos e o espírito se encham de um prazer maravilhoso."606 Eles são a fonte de toda a qualidade agradável a ser admirada.

Em 1533, no seu Panegírico de D. João III pronunciado em Évora, o grande humanista João de Barros qualificava o Rei de músico - e ele não sabia tocar nenhum instrumento, que se saiba... O famoso esteta, tratadista e desenhador Francisco de Holanda (que lia em 1547 o Della Pittura), um paradigma do Renascimento português senão sua figura mais representativa, ia a ponto de inventar o seu oposto: desmúsico, para designar como um modismo culto de côrte o homem imperfeito ou pouco harmonioso, de ar desagradável no aspeto físico e alma inquieta. A sombra de Alberti estava sem dúvida por detrás destes ensaios semânticos.

Por estranho que pareça, era descoberta recente no meio cultural do país. Ao contrário de um Brunelleschi, Fra Angelico, Paolo Toscanelli, Mariano Tacola, o iluminador Attavante, Francesco di Giorgio Martini - tão apreciado por D. João II 607 -, Leonardo da Vinci que o próprio Vasari

606 Para o texto de Alberti utilizamos a recente edição da Fundação Calouste Gulbenkian, Da Arte Edificatória, Lisboa, 2011, com introdução, notas e revisão disciplinar de Mário Krüger e tradução do latim de Arnaldo Espírito Santo; a passagem referida encontra-se na p. 597.

607 PEDRO DE ABOIM INGLEZ BRAAMCAMP CID, A Torre de S. Sebastião de Caparica e a arquitetura militar do tempo de D. João II, tese de Mestrado em História da Arte por nós 
diz haver trabalhado para Portugal, ou o escultor Andrea Sansovino que passou entre nós os 9 anos de tumultos políticos e religiosos em Florença 608 -, Alberti nunca é citado durante todo o Quattrocento. O que nos leva a crer que tratou-se verdadeiramente de uma descoberta feita em Paris por volta de 1515 pelo jovem brilhante estudante de Matemáticas, Filosofia, Teologia e Artes Francisco de Melo através da edição parisiense do De re aedificatoria publicada em 1512 por Geoffroy Tory, um nome bem conhecido em Portugal por seus trabalhos sobre a escrita romana para uso na Iluminura. Subitamente, tudo muda (procuraremos adiante ver como e porquê). Pouco após o regresso de Paris de Francisco de Melo, que terminou os seus estudos depois de 1521, Alberti é uma celebridade.

O cronista e poeta um pouco antiquado, mas atento, Garcia de Resende - grande cortesão de Évora e sem dúvida amigo próximo de Francisco de Melo, que era seu parente - escreveu de 1531 a 1533 a curiosa Miscellania, para exprimir o espanto face às mudanças do "nosso tempo e idade". Aí diz, como exemplos da nova cultura: Vimos o gram Michael,/Alberto, e Raphael... O segundo nome tem sido interpretado como referindo-se a Dürer, o que não faz sentido: era ainda demasiado cedo para o colocar ao mesmo nível de um Michelangelo e dum Rafael, Resende fala apenas de italianos, e o contexto alude claramente às 3 grandes artes, Escultura, Arquitetura e Pintura. Quanto a nós, não pode haver dúvida que se trata de referência a Alberti, aliás a primeira entre nós.

A Biblioteca Pública Municipal do Porto guarda um exemplar do De re aedificatoria na ed. de Paris, 1512, em que uma nota autógrafa diz ter sido comprado em Roma em 1534 pelo cortesão e arquiteto amador Gonçalo Baião, com o duplo interesse de mostrar que o desejo do tratado não se limitava ao círculo humanista de Évora e que a editio princeps já se esgotara nos livreiros romanos.

Há, decerto, outras citações de Alberti em Portugal, mas tardias e como uma "auctoritas" que dispensa apresentação. O tratado Dialoghi di Amore

dirigida na Universidade Nova de Lisboa, 1998 (publ. Edições Colibri/Instituto de História da Arte, UNL, Lisboa, 2007, p. 372).

608 RAFAEL MOREIRA, “Andrea Sansovino au Portugal, 1492-1501”, in Revue de l'Art, 133, CNRS, Paris, 2001, pp. 33-8. 
publicado em italiano (Roma, 1545) pelo médico cristão-novo português Leon Abravanel - mais conhecido como Leão Hebreu - é um caso. Segundo o Prof. Pina Martins baseia-se no diálogo Hecatomfila d'Amore de Alberti que teve grande difusão na Itália e França e seria mesmo citado por Faria e Sousa na edição das "Rimas" de Camões publicada em Lisboa em 1685. ${ }^{609}$ Não refiro a fachada do palácio dos Duques de Bragança em Vila Viçosa - uma réplica alongada do Palazzo Rucellai de Alberti -, de 1535-37, porque deve ter sido traçada pelo engenheiro-arquiteto italiano de formação albertiana, Benedetto da Ravenna. ${ }^{610}$

Temos portanto de colocar a questão: como e por que razão o nome de Leon Battista Alberti, ainda um total desconhecido no fim do reinado de D. Manuel I, é apresentado como uma revelação 10 anos mais tarde por Garcia de Resende? Que acontecimento em concreto - pois não podia deixar de ser tal - justifica uma tão rápida, súbita e radical mudança de valor?

Voltemos à oração de Francisco de Melo de 1535, o momento de apogeu desta descoberta do De re aedificatoria apresentado como metáfora da doutrina de Estado diante dos representantes da nação inteira, para tentar ver mais claro. E comecemos por alguns dados sobre o seu autor.

Francisco de Melo era um fidalgo de alto nível da nobreza de Évora, da família dos Melo, uma das mais importantes do Reino, filho mais novo do alcaide-mor de Olivença. Formado em Matemáticas pela Universidade de Lisboa, recebeu do rei $\mathrm{D}$. Manuel uma bolsa para continuar seus estudos em Paris, de 1514 a cerca de 1520, onde obteve no Collège de Montaigu os mais altos graus em Matemáticas, Artes, Filosofia e Teologia com os mestres mais reputados, como Gaspar Lax, Jean Fernel - que já difundia o Comentariolus de Nicolau Copérnico e sua teoria heliocêntrica (por exemplo, na Cosmotheoria que dedicou em 1528 a D. João III) - e Pierre Brissot, que veio morrer a Évora a 1522 e foi amigo de Oronce Finé, autor em 1525 do primeiro mapa corográfico da França.

609 JOSÉ VITORINO PINA MARTINS, Humanisme et Renaissance de l'Italie au Portugal. Les deux regards de Janus, Fund. Calouste Gulbenkian, Lisboa-Paris, 1989, pp. 372 e 401.

610 RAFAEL MOREIRA, "Uma Cidade Ideal em Mármore. Vila Viçosa, a primeira corte ducal do Renascimento português", in rev Monumentos, 6, DGEMN, Lisboa, 1997, pp. 48-53. 
Em 1515, apenas com 30 anos de idade, Lax dedicava-lhe a sua Arithmetica Speculativa e elogiava-o em termos encomiásticos: "Raros têm iguais conhecimentos, não apenas em aritmética e geometria, mas também em astrologia [astronomia], cosmografia ou em vidros ópticos, de tal modo que ninguém te propõe um problema, mesmo difícil, que não o descubras por evidentes e poucos meios.” Luís Vives cita-o numa carta a Erasmo em 1520, dizendo que ele conhece "toda a matemática, e consagrou-se com igual sucesso às letras polidas”.

Datam de 1514-17 as suas obras mais conhecidas: os Comentários sobre a perspetiva e a especulária de Euclides e um Comentário ao De Incidentibus in Humidis de Arquimedes, uns 150 in-fólios encadernados em 1521 para oferecer ao seu protetor D. Manuel, iluminados em fino pergaminho a azul e ouro, escritos em excelente latim, descobertos há poucos meses no Arquivo Municipal de Stralsund, na costa báltica da Alemanha. ${ }^{611}$ Ainda em estudo, talvez seja o próprio livro oferecido em 1667 pelo cosmógrafo-mor Luis Serrão Pimentel ao embaixador espanhol Marquês de Heliche, comprado no século XVIII em Madrid por um general alemão apaixonado pela matemática que o deixou à sua cidade natal. A Biblioteca Nacional possui desde o século XIX uma cópia em papel, assaz vulgar, do Setecentos. Foi aí que tive a surpresa de encontrar a primeira menção feita por um autor português ao De Architectura de Vitrúvio, que Francisco de Melo deve ter lido numa das edições ilustradas de Fra Gocondo, editadas em Veneza em 1511 e Florença em 1513. ${ }^{612}$

Eis um fato que mostra bem o interesse de Francisco de Melo pela arte do Renascimento, o recente modo ao romano. Nascido e criado no mais antigo palácio de Évora - o castelo medieval da cidade doado em 1390 à sua família (hoje pertença dos Duques de Cadaval), aumentado e muito embelezado por jardins “à italiana” pelo seu avô, o Conde de Olivença, que também fundou ao lado a igreja dos monges de Santo Elói, ou Lóios (1485) -, ele frequentou o círculo erudito de artistas e amadores de arte animado pelo cónego parisiense Jean Petit e pelo humanista André de

611 Agradeço à Dr ${ }^{a}$ Lígia Martins, diretora da secção de "Reservados" da Biblioteca Nacional de Portugal, os dados que gentilmente nos forneceu sobre esta descoberta.

612 RAFAEL MOREIRA, “A Arquitetura do Renascimento...” op. cit., pp. 236-7 e nota 60. 
Resende, em que pontificava o maior escultor renascentista do país, o normando Nicolau Chanterene - o insignis sculptor Cantarenus a que enviava saudações o célebre humanista flamengo Clenardo - que faria para ele em 1536 um túmulo “à romana”, simples e geométrico como seria o seu gosto pessoal, na igreja familiar dos Lóios, onde repousa.

Mas era a Matemática que enchia a sua vida. Gil Vicente diz a seu respeito que sabe ciençia avondo (abundantemente), no "Auto da Feira", e que era o milhor mathematico no reyno ("Trovas a Filipe Guillén"), de quem terá sido discípulo e amigo Pedro Nunes.

É momento de perguntar: que relação direta podemos estabelecer entre o cientista Francisco de Melo e a obra de L. B. Alberti, cuja ideologia filosófica, moral, política e até artística impregna todo o seu discurso de 1535? É o ponto central das nossas questões.

É necessário, para isso, falarmos do quase desconhecido Codex 136 in scrinium da Staats- und Universitat Bibliothek de Hamburgo, descoberto em 1935 e descrito em 1946 por Luís Silveira.

Trata-se de um pequeno manuscrito de grande luxo in-octavo constituído por 55 fólios do mais fino pergaminho, iluminado a ouro, azul ultramarino e verde esmeralda, com a caligrafia a negro e forte vermelho, com um palmo de altura (22 cms): uma minúscula jóia, avaliada em 3 milhões de Euros.

Encadernado em couro antes de 1724, quando já se encontrava na Alemanha, fora adquirido em Madrid por um diplomata dinamarquês amante de livros antigos entre 1698 e 1706, o qual o ofereceu à Biblioteca de Hamburgo. Mas se a capa é factícia, o bordo externo das folhas é dourado desde a origem em ouro puro. O estado de conservação é perfeito, sinal de que não foi muito usado.

O seu conteúdo é surpreendente. Apenas uma lista de 1.531 topónimos de Portugal postos em ordem alfabética, de Almada a Zoio. São cidades, vilas, aldeias, lugares, províncias, montanhas e rios, com cada linha dividida por 3 colunas: uma com o nome, e as duas outras com a longitude e a latitude, expressas em graus e frações.

A primeira página ocupa-a uma riquíssima iluminura, que é ao mesmo tempo dedicatória e marca de posse: aí se lê em baixo, em belas capitais latinas a ouro, sobre fundo verde, a cor do Cardeal D. Afonso, arcebispo 
de Évora (1523-40), sobre a qual estão as suas armas, artisticamente pintadas. Não pode haver dúvida de espécie alguma que o livrinho pertenceu e foi oferecido ao jovem Cardeal D. Afonso (1509-40), irmão mais novo de D. João III, quando ele ainda era cardeal de S. Brás e já arcebispo da diocese eborense, aos 18 anos de idade.

Contra a unanimidade dos raros autores que se ocuparam desta pequena obra-prima, que deixam em aberto a questão, o recente - e excelente - livro da geógrafa Suzanne Daveau mostrou que a única pessoa em Portugal em condições de realizar os estudos e observações conduzindo à sua elaboração - executado no scriptorium real de iluminura e caligrafia, onde brilhariam António de Holanda e seu filho Francisco 613 - não podia ser outro senão o cientista, recém-chegado de Paris e mestre de matemáticas do Infante: o próprio Francisco de Melo em pessoa. A obra corresponderia, assim, a um pedido, ou desejo, do Cardeal, que as fontes descrevem como "muito estudioso e sério" apesar de sua idade, e com "uma prudência de velho". 614

Não partilhamos da opinião de S. Daveau e K. Kaufman, para quem o Códice de Hamburgo seria um simples índex para ajudar a situar os lugares - quem quereria saber a longitude e latitude exatos de 1531 terras, algumas desaparecidas ou mesmo desconhecidas? - colocadas num mapa de grandes dimensões do território português, que se perdeu. Pensamos, pelo contrário, que um tão belo livro era a obra em si mesma, o objeto dos esforços de Francisco de Melo para descrever por uns quantos números e palavras, sem a ajuda do desenho, a geografia de Portugal: uma carta corográfica virtual, em que se pudesse localizar qualquer topónimo unicamente recorrendo às suas mais exatas coordenadas possíveis, sem ser preciso abrir um enorme mapa de vários metros de dimensão, difícil - senão impossível - de abrir, desdobrar, e debruçar-se sobre ele.

613 RAFAEL MOREIRA, "Novos dados sobre Francisco de Holanda", in Sintria, I-II, Câm. Munic. de Sintra, 1983, pp. 679-692.

614 LUÍs SILVEIRA, Portugal nos Arquivos Estrangeiros.I, Manuscritos portugueses da Biblioteca Estadual de Hamburgo, Lisboa, 1946; Kevin Kaufman, An Early Portuguese Geographical Index. The Longitudo et Latitudo Lusitaniae and its Relation to 16th-Century Mapping Techniques, Univ. de Wisconsin, Madison, 1988; e sobretudo SUZANNE DAVEAU, Um mapa corográfico de Portugal (c.1525). Reconstituição a partir do Códice de Hamburgo, Centro Estudos Geográficos, Faculdade de Letras, Lisboa, 2010. 
Temos aí um facto de significado capital: o livro substitui o desenho. A escrita e os números (de que Suzanne Daveau conseguiu, com admirável inteligência, decifrar a notação algo enigmática das frações) tomam o lugar do gráfico ou pintado. Dir-se-ia que Francisco de Melo "digitaliza" em signos binários e intelectuais, apenas pelo uso da razão abstrata, as formas visíveis em desenhos e cores de uma carta geográfica. Ele informatiza em dados escritos a forma e as relações espaciais dos lugares referenciados, literalmente traduzindo a imagem por palavras/números como num programa de computador, substituindo o visual pelo verbal e sua sequência numérica. O Códice de Hamburgo é, em si mesmo, o mapa mais completo e fácil de ler do país inteiro. Fica-se estupefacto, mais do que surpreso, perante uma tão extraordinária modernidade.

E, de repente, o paralelismo se impõe com uma outra "planta escrita": a de Alberti na sua Descriptio Urbis Romae, composta cerca de 1448 como um gráfico ou sistema de pontos (o frenesi de escritos recentes a seu respeito ainda discute se existiu ou não uma planta real, anterior ou feita mais tarde). Alberti, que se tinha recusado a ilustrar o seu $D e$ Re Aedificatoria, e aplicara idêntico sistema "de pontos" para transpor as formas tridimensionais do corpo humano em algoritmos no De Statua (c.1450) - baseado, é certo, nos métodos cartográficos de Ptolomeu e Marino de Tiro - recria ou inventa um método plenamente fiável, científico até, para transpor em formato numérico o real.

Como escreveu Mario Carpo: “Alberti's Description is no literary description, nor may it count as a textual recital: it is indeed a map, albeit encrypted in a sequence of numbers. (...) When one opens the book and looks for the plan some disappointment is inevitable. A map of a city is a drawing. As it stands, Alberti's Descriptio Urbis Romae is a brief text, followed by a list of numbers (geographical coordinates in the numerical format of degrees, minutes, and occasionally fractions), and accompanied by two elementary, geometrical diagrams illustrating an instrument to be used to draw the map. The map, however, is not there." 615

615 MARIO CARPO, "Alberti's vision and a plan of Rome", in Albertiana, VI, SILBA/L. Olschki, Florença, 2003, pp. 210-1. 
Tudo o que há é um texto de 6 parágrafos onde ele apresenta o seu método (pactus) para desenhar os levantamentos de Roma sobre uma superfície do tamanho que se desejar, o desenho do instrumento matemático que diz ter inventado para o fazer "o mais elegante e cómodo" possível, e uma lista de 176 pontos (ângulos dos muros da cidade, portas, templos, edifícios públicos) à volta de um ponto central (caput in centro). Fazendo girar uma régua (radius) dividida em 50 partes, fixa no centro, marcam-se as coordenadas de cada ponto escolhido em relação ao perímetro (borizon). O desenho se obtém unindo esses pontos por linhas, retas ou curvas segundo os casos. E é tudo.

As semelhanças com o sistema de Francisco de Melo são totais. Trata-se tão só de delimitar o campo geométrico da área a medir um círculo de 48 raios (gradi) para Alberti e a urbe de Roma, um retângulo contendo a superfície de Portugal dividido em retângulos mais pequenos para Melo -; a escolha de um centro - o Capitólio para Alberti, a vila central de Portugal, Tomar, para este (ainda que, como muito bem estabeleceu Suzanne Daveau, o real centro tenha sido a península de Setúbal, que concentra 29 topónimos ao longo de $30 \mathrm{kms}$, decerto por razões práticas); tirar as coordenadas com o astrolábio noturno, sobre a lua ou a estrela polar, por um cuidado de exata precisão que o sol não permite; e medir e notar os lugares, de visu para Alberti, pelo cálculo das distâncias segundo o percurso dos trajetos viários e mapas das comarcas para Melo. A única variante, claro, é o número dos lugares notados: 1531 para o português contra 176 para o italiano - a diferença entre um país e uma cidade. Não se trata dum número casual, estamos convictos, mas simbólico: Francisco de Melo quis homenagear o Cardeal seu mecenas pondo o número do ano em que lhe oferecia a obra, no que mais uma vez nos afastamos de Daveau.

A conclusão se impõe por si: Francisco de Melo tomou conhecimento em Paris de algum manuscrito contendo uma cópia da Descriptio Urbis Romae - talvez o da Biblioteca Marciana de Veneza, que recolhe os escritos matemáticos de Alberti em fins do século XV, segundo o magnífico estudo da tradição textual da Descriptio feita por Francesco 
Furlan616 - e decidiu aplicá-la a Portugal, estimulado pelos estudos de seu amigo Oronce Finé. O que nos permite datar a longa execução dos estudos preparatórios do Códice de Hamburgo de entre o seu regresso à pátria, cerca de 1521, e a sua morte súbita em 1536, pouco após ter sido nomeado pelo Rei primeiro bispo de Goa, em 1535 - mas aonde não chegou a partir, fosse por causa da saúde, fosse pelos inúmeros deveres na corte.

Fosse como fosse (e em 1531, data que julgamos ser a da execução do Códice, era ainda um homem jovem: tinha 50 anos, e o Cardeal apenas 31, o que reforça o simbolismo pessoal do ano), é a primeira vez que o nome de Alberti, se bem que não citado - era-o então por Garcia de Resende -, aparece em completa evidência. Para quem fora o primeiro a citar, com todas as letras, o de Vitrúvio num passo concreto, o feito de Francisco de Melo não é pouca coisa.

Deixamos para outra ocasião o estudo de um problema interessante: o mais antigo mapa gravado de Portugal - o que ofereceu o bibliotecário da Vallicelliana, Aquiles Estaço, ao cardeal Guido Ascanio Sforza, impresso em Roma em 1561 (com uma reedição de 1565) pelo matemático Fernão Álvaro Seco - é uma versão em largo formato $(60$ x $80 \mathrm{cms})$ do mapa de Francisco de Melo como bem viu Suzanne Daveau, de que copia o contorno da costa e rios, bem como o desvio para Leste do litoral a norte do Mondego e numerosos topónimos do Códice de Hamburgo. ${ }^{617}$ Deve ter sido a impressão de uma das muitas versões que terão sido feitas do mapa de Francisco de Melo, sem lhe corrigir os erros: e o facto de Fernão Álvaro Seco ser matemático sugere que fosse seu discípulo.

Após este surto inicial ainda de época manuelina e em Paris, o renome da figura gigante de Alberti reaparece meia dúzia de anos mais tarde em outro contexto, o da arte do Alto Renascimento. Passada a "leitura científica" de Francisco de Melo, o De re aedificatoria parece ter sido submetido a uma

616 FRANCESCO FURLAN, "Descriptio Urbis Romae. Édition critique et Introduction", op. cit., pp. 125-57.

617 SUZANNE DAVEAU, ob. cit., p. 198; ARMANDO CORTESÃO e AVELINO TEIXEIRA DA MOTA, Portugaliae Monumenta Historica, Lisboa, 1960, II, pp. 77-86. Daveau põe a execução do Ms. de Hamburgo em 1525, ano em que D. Afonso recebeu o capelo de cardeal. 
verdadeira e pura "leitura artística" pelos próprios arquitetos, mas sobretudo pelos mecenas e encomendantes: já vimos o caso precoce de Gonçalo Baião, que foi "criado" dos Cardeais-Infantes D. Afonso e seu irmão D. Henrique; mas há que lembrar o próprio rei D. João III, que a partir do episódio de Mazagão em 1541 converte-se à arquitetura a ponto de ser chamado rei-arquiteto pelos seus contemporâneos, como o $\mathrm{P}^{\mathrm{e}}$. Francisco de Monzón.

Nesse ano, querendo transformar os seus mestres-pedreiros em verdadeiros arquitetos "ao romano", promove uma série de traduções e edições de livros de arquitetura: Vitrúvio, pedido ao matemático Pedro Nunes ${ }^{618}$ - ainda na tradição da receção pelas ciências matemáticas -, Sagredo (que teve 3 edições em menos de 2 anos, facto único entre nós), o tratado de Frontino sobre os aquedutos, e Alberti, claro está. Encomendou-o ao mestre latinista André de Resende, que acabou de o traduzir em 1547, em que o levou em mãos ao palácio de inverno em Almeirim: lembra-o na Dedicatória ao Rei da sua História da Antiguidade da Cidade Évora (sic) de 1553, e relembra-o no seu testamento, onde refere o Livro de Arquitetura, ou tradução da Arquitetura de Leão Baptista, de que deixa cópia ao filho. Ainda era referido como existente por autores do fim do século XVI, sinal evidente que foi de facto traduzido e posto à leitura pública - mas decerto levado para Espanha, com tantos outros, por Juan de Herrera em 1581, onde poderá ainda existir o manuscrito. O que não impede que tenha sido a primeira tradução feita fora da Itália.

Durante quase meio século o livro esteve acessível a todos os que não falavam o latim e o italiano na biblioteca da "Aula de Arquitetura" do Paço da Ribeira. Aí foi lido, estudado e meditado por gerações de jovens arquitetos, tendo tido sem dúvida uma forte influência sobre a viragem que sofre a arquitetura portuguesa no meado do século XVI, da plenitude do Alto Renascimento para as formas simples, despojadas, desornamentadas do "estilo chão": esse gosto pelos volumes cúbicos, superfícies lisas, rejeição do ornato supérfluo, falta de interesse pelas ordens das colunas clássicas, purismo geométrico, cuidado das proporções e medida das linhas retas

618 JULIAN JACHMANN, Vitruvrezeption im kontext mathematischer wissenshaften. Die Architekurbücher des Walter Hermann Rytts, Ibidem, Verlag Stuttgart, 2006. 
que a Contra-Reforma e o reforço da Arquitetura Militar impõem até à vinda da dinastia dos Habsburgo, de que o melhor exemplo é o caso extraordinário de António Rodrigues e seu tratado português de arquitetura.

Após ter atingido o mais alto prestígio, segue-se o silêncio: o nome de Alberti cai no olvido, ou mesmo em desgraça, com a proibição pela Inquisição da leitura do seu livro no Índex de 1581, pelo elogio das igrejas de planta circular com um altar único ao centro que Trento proibira.

A reabilitação apenas vem com a nova dinastia mais cosmopolita dos Filipes de Espanha e o regresso de jovens arquitetos enviados a Itália a aprender e ver arquitetura. Em 1580 chega Baltasar Álvares com o conhecimento direto da obra albertiana construída, como S. André de Mântua, cujos tramos rítmicos e harmonias musicais lhe inspiram a igreja do Mosteiro de São Vicente-de-Fora em Lisboa, que tão grande influência terá no Nordeste do Brasil em todo o século XVII (São Bento e Santa Teresa em Salvador, para só citar dois exemplos maiores). Pouco após, cerca de 1590, João Batista Lavanha cita-o como um mestre no tratado Da Arquitetura Naval. E é ainda como tratadista que Mateus do Couto lhe faz o elogio no Tratado de Arquitetura - resumo das lições que deu na Aula do Paço da Ribeira em 1631 - entre os demais arquitetos: ...o grande Leon Bapt ${ }^{a}$, cabeça de todos elles.

"E por esses mesmos anos, no seu curioso manual Poesia e Pintura, ou Pintura e Poesia, escrito em Beja em 1633, o Pe. Manuel Pires de Almeida tomava por base o De Pictura de Alberti (que leu e cita na tradução italiana de Cósimo Bártoli, Veneza, 1568), como o ponto de partida do confronto entre ambas as artes."619

É difícil exagerar, ou sequer analisar como devíamos, a influência que exerceu entre nós e no Brasil (mas menos na Índia, é curioso) a figura, a obra e os escritos do polimorfo Leon Battista Alberti, de que ainda passados dois séculos e do outro lado do Atlântico a voz - ou o olho alado - se fazia sentir com toda a força.

619 ADMA MUHANA, Poesia e Pintura ou Pintura e Poesia, tratado seiscentista de MANUEL PIRES DE ALMEIDA, EDUSP (Editora da Universidade de São Paulo), São Paulo, 2002. 